\title{
Keragaman Lumut pada Marga Pandanus di Taman Nasional Ujung Kulon, Banten
}

\author{
Florentina Indah Windadri \\ Herbarium Bogoriense, Bidang Botani, \\ Pusat Penelitian Biologi, Cibinong Science Centre - LIPI \\ Jl. Raya Jakarta - Bogor km 46, Cibinong, BOGOR
}

Diterima 12-03-2008

Disetujui 04-01-2009

\begin{abstract}
Ujung Kulon National Park is one of conservation area in Banten Province. A research on bryophytes that grow on pandanus substrat in this area have been done at March to April 2008. The surrounding areas methode used on this research. In the collections found 9 species usually growth on bark of Pandanus dubius. Two species was reported as the important species, because one species (Fissidens teysmanianum Doz. \& Molk) is endemic species in Java and the other (Calymperes cougiense Besch.) as abundant species in Malesia and it is only found in Polynesia region.
\end{abstract}

Key words: bryophyte, conservation area, diversity, Pandanus, substrate

\section{PENDAHULUAN}

Taman Nasional Ujung Kulon merupakan salah satu kawasan konservasi di Indonesia yang memegang peranan penting dalam menjaga kelestarian sumber daya hayati dan keseimbangan ekosistem. Kawasan konservasi ini resmi ditetapkan sebagai Taman Nasional pada tahun 1992. Luas areanya 120.551 ha, terdiri dari 76.214 ha berupa daratan dan 44.337 ha lautan (Maulana et al, 2004). Tipe ekosistem di kawasan Taman Nasional ini terbagi menjadi tiga yaitu ekosistem perairan laut, pantai, dan daratan. Pada ekosistem daratan dapat ditemukan ekosistem hutan hujan tropis dataran rendah yang terluas di Jawa Barat. Keanekaragaman jenis flora phanerogamnya telah terdata dengan baik dan dilaporkan ada sekitar 700 jenis, 57 jenis diantaranya merupakan tumbuhan langka (Sriyanto et al, 2003). Pada ekosistem pantai umumnya didominasi oleh suku Pandanaceae, namun keragaman jenisnya belum pernah terdata secara lengkap.

Lumut merupakan kelompok tumbuhan epifit yang banyak ditemukan tumbuh di batang pohon, kayu mati, kayu lapuk, tanah, atau batuan, dengan kondisi lingkungan lembab dan penyinaran yang cukup. Penelitian keanekaragaman lumut telah banyak dilakukan namun penelitian tentang keanekaragaman lumut yang tumbuh pada suku Pandanaceae

Telp: 021-876-5066, Fax. 021-8765063

Email: herbogor@indo.net.id khususnya pada marga Pandanus hingga kini belum pernah dilaporkan. Oleh karena itu perlu dilakukan pendataan keanekaragaman jenis lumut khususnya yang hidup pada marga Pandanus. Dipilinnya marga Pandanus sebagai substrat lumut dalam penelitian ini karena marga ini mempunyai perawakan pohon yang bercabang. Dengan tipe perawakan demikian dimungkinkan ketiak percabangan merupakan tempat yang relatif lebih lembab dan akan ditemukan tumbuhan epifit seperti lumut.

\section{BAHAN DAN METODE}

Penelitian dilakukan dengan metode jelajah (Rugayah et al, 2003) yaitu pengamatan dilakukan pada setiap individu pandan yang ditemukan di lokasi penelitian. Apabila ditemukan lumut yang tumbuh menempel pada pohon pandan maka diamati dan dikoleksi. Koleksi lumut (pengambilan spesimen contoh) dilakukan dengan menyayat koloni lumut berikut substratnya, dan kemudian dimasukkan ke dalam amplop. Proses selanjutnya spesimen dikeringanginkan dengan cara membuka amplopnya. Spesimen yang sudah kering dibungkus kembali dan selanjutnya dibawa ke Herbarium Bogoriense untuk keperluan identifikasi. Sedangkan untuk tumbuhan inangnya ada beberapa catatan lapangan yang dicatat antara lain nama lokal jenis pandan sebagai substratnya, bagian tumbuhan yang ditempeli lumut 
(akar, batang, ranting atau daun). Identifikasi dilakukan di Laboratorium Kriptogam Herbarium Bogoriense dengan menggunakan mikroskop. Beberapa buku acuan yang digunakan antara lain ' $A$ Handbook of Malesia Mosses, Volume 1 dan 2' (Eddy1988; Eddy 1990), 'Mosses of The Philippines' (Bartram 1939), 'Mosses and Liverworts of Hong Kong, Volume 1' (So 1995), dan mencocokkan dengan spesimen koleksi yang tersimpan di Herbarium Bogoriense. Spesimen yang sudah teridentifikasi kemudian diproses sebagai koleksi herbarium untuk menambah jumlah koleksi yang tersimpan di Herbarium Bogoriense.

Lokasi penelitian berada di bagian tenggara dari kawasan Taman Nasional Ujung Kulon yang termasuk dalam wilayah Resort Karang Ranjang. Pemilihan lokasi penelitian ini didasarkan pada informasi dari petugas Kantor Taman Nasional Ujung Kulon yang menyatakan bahwa tumbuhan pandan paling banyak ditemukan di tepi Pantai Selatan. Adapun kawasan hutan yang dijelajahi antara lain hutan Karang Ranjang, Cisimping, Ciseuseupan, Tereleng dan Binua. Kawasan hutan ini mempunyai topografi datar hingga agak berbukit dengan lantai hutan sebagian besar berawa. Tipe hutannya berupa hutan dataran rendah dan hutan pantai. Sedangkan waktu penelitian dilakukan pada bulan Maret s/d April 2006.

\section{HASIL DAN PEMBAHASAN}

Secara umum tumbuhan yang mendominasi hutan dataran rendah di area penelitian adalah kelompok suku
Arecaceae khususnya pohon langkap ( Arenga obtusifolia) dan rotan (Daemonorops spp.\& Calamus spp). Disamping itu juga ditemukan dua jenis pandan yaitu cangkuang (Pandanus furcatus) dan Pandanus nitidus. Sedangkan hutan pantainya didominasi oleh kelompok suku Pandanaceae yang banyak ditemukan di sepanjang tepi pantai selatan dengan kondisi lingkungan terbuka, panas dan kering. Di lokasi ini ditemukan dua jenis pandan yaitu pandan (Pandanus tectorius) merupakan jenis yang paling banyak dijumpai dan bidur (Pandanus dubius) yang tumbuh di area lembab tepi pantai dan ini hanya ditemukan pada satu tempat saja. Hommel (1987) melaporkan bahwa terdapat lima jenis anggota suku Pandanaceae di kawasanan Taman Nasional ini yaitu Freycinetia cf. imbricata, Pandanus bidur, Pandanus furcatus, Pandanus nitidus, dan Pandanus tectorius. Namun pada pengamatan di lokasi penelitian, dua jenis di antaranya tidak ditemukan yaitu Freycinetia cf. imbricata dan Pandanus nitidus.

Dalam kaitan asosiasi lumut dengan kelompok suku Pandanaceae, tidak semua pandan yang dijumpai di kawasan Taman Nasional ini ditumbuhi oleh lumut. Lumut hanya dijumpai pada beberapa pohon terutama pandan yang tumbuh ditempat lembab dan teduh. Berdasarkan hasil koleksi, lumut yang tumbuh di berbagai pohon marga Pandanus diidentifikasi sebagai 15 jenis lumut (Tabel 1.)

Dari Tabel 1 dapat dilihat bahwa bidur (Pandanus dubius) merupakan habitat yang cukup baik untuk

Tabel 1. Daftar jenis lumut yang tumbuh pada marga Pandanus di Taman Nasional Ujung Kulon, Banten

\begin{tabular}{|c|c|c|c|}
\hline Suku & Nama Jenis & Habitat & Lokasi \\
\hline Calymperaceae & Calymperes cougiense Besch. & Akar Pandanus dubius & Karang ranjang \\
\hline Calymperaceae & Calymperes crassinerve (Mitt.) Jaeg.. & Akar Pandanus dubius & Tereleng \\
\hline Calymperaceae & Calymperes cougiense Besch. & Batang Pandanus nitidus & Pengorok \\
\hline Fissidentaceae & Fissidens teysmanianus Doz. \& Molk. & Batang Pandanus furcatus & Cisimping \\
\hline Hypnaceae & Vesicularia montagnei (Bel.) M.Fleisch. & Batang Pandanus furcatus & Cisimping \\
\hline Thuidiaceae & Thuidium cf kiasense & Akar Pandanus nitidus & Pengorok \\
\hline Bazzaniceae & Bazzania sp. & Akar Pandanus dubius & Karang ranjang- \\
\hline Frullaniaceae & Frullania sp. & Akar Pandanus dubius & Karang ranjang \\
\hline Frullaniaceae & Frullania sp. & Batang Pandanus tectorius & Tereleng \\
\hline Frullaniaceae & Frullania cf muscicola & Batang Pandanus tectorius & Karang ranjang \\
\hline Frullaniaceae & Frullania sp. & Batang Pandanus nitidus & Pengorok \\
\hline Lejeuneaceae & Lopholejeunea eulopha (Tayl.) Schiffn. & Akar Pandanus dubius & Karang ranjang \\
\hline Lejeuneaceae & $\begin{array}{l}\text { Leucolejeunea xanthocarpa (Lehm. } \\
\text { Linderb.) Evans }\end{array}$ & Akar Pandanus dubius & Karang ranjang \\
\hline Radulaceae & Radula sp. & Batang Pandanus furcatus & Cisimping \\
\hline Radulaceae & Radula sp. & Akar Pandanus nitidus & Pengorok \\
\hline
\end{tabular}




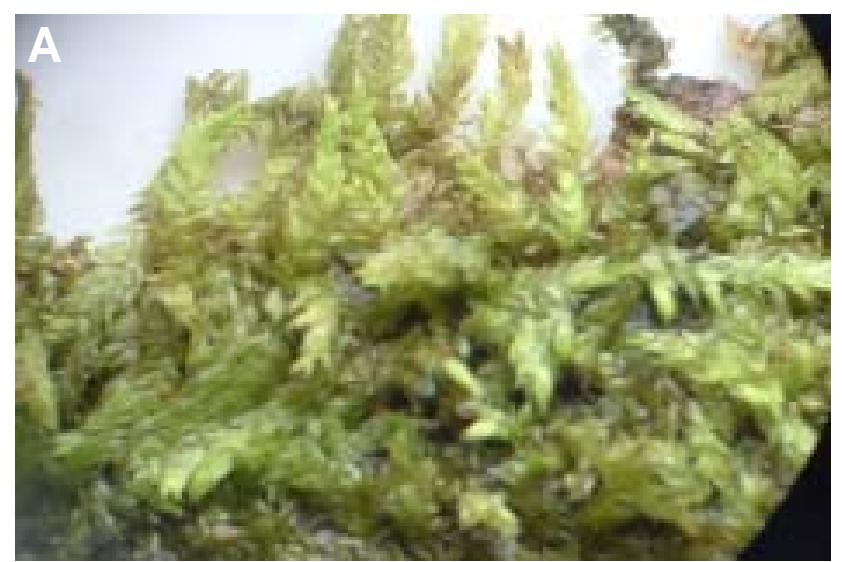

Vesicularia montagnei

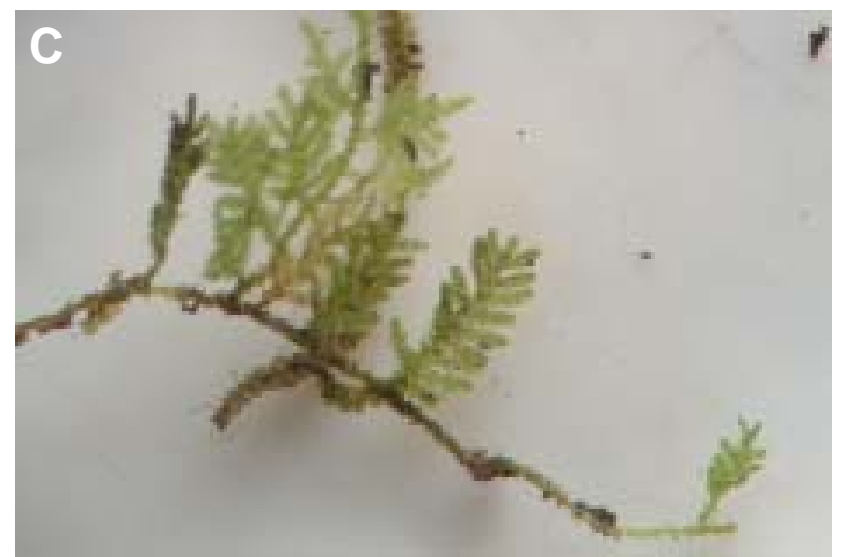

Thuidium kiesense

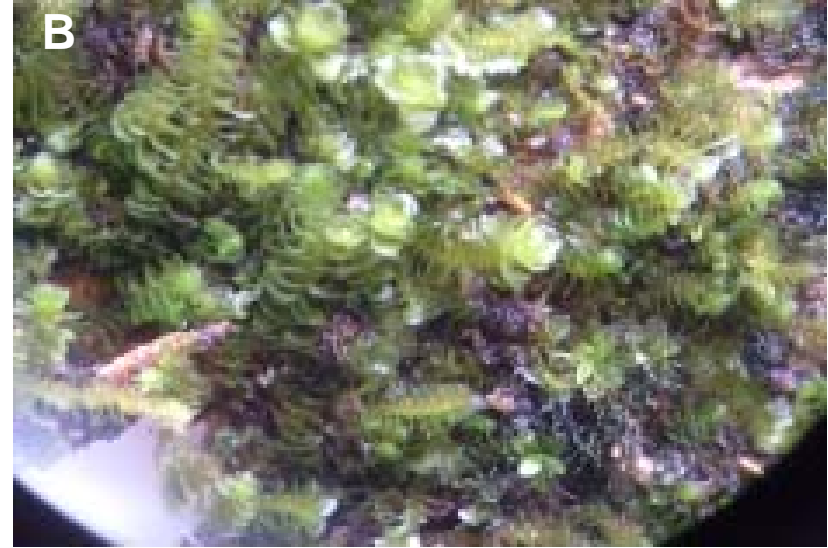

Leucolejeunea xanthocarpha

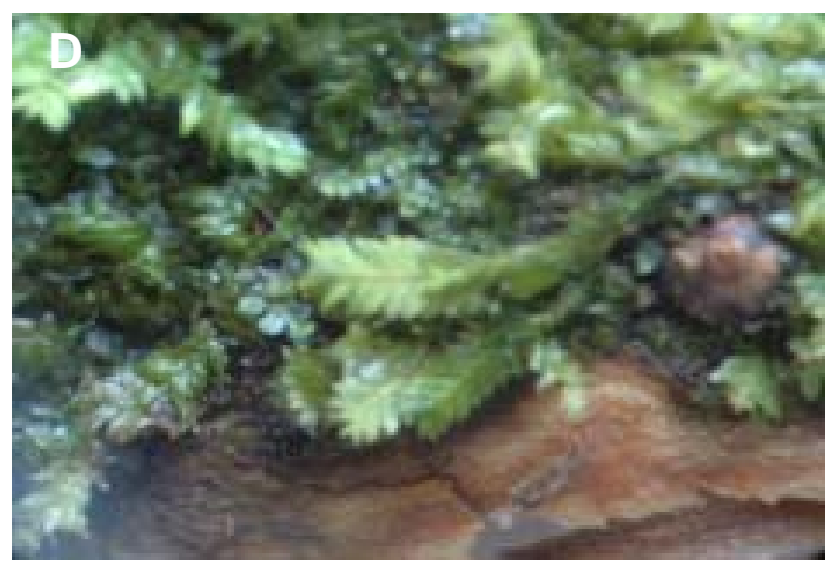

Fissidens teysmanianum

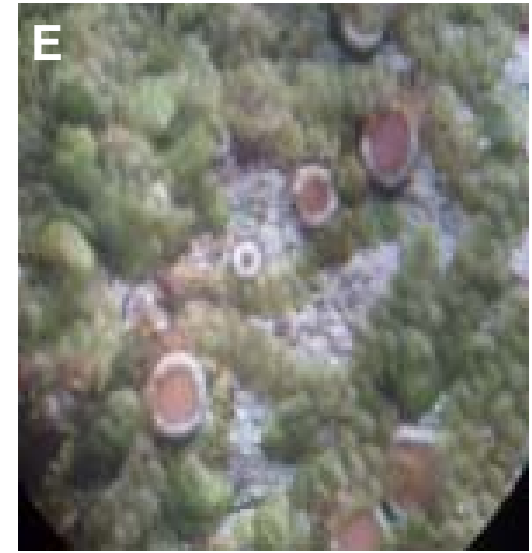

Lopholejeunea eulopha tercampur apothecia Dimerella $s p$.

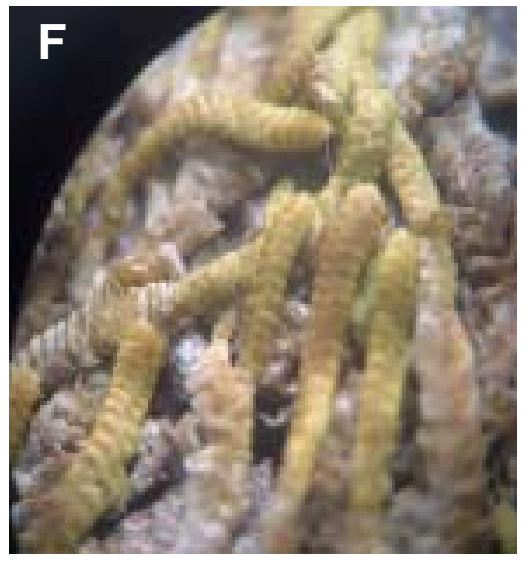

Frullania $s p$.

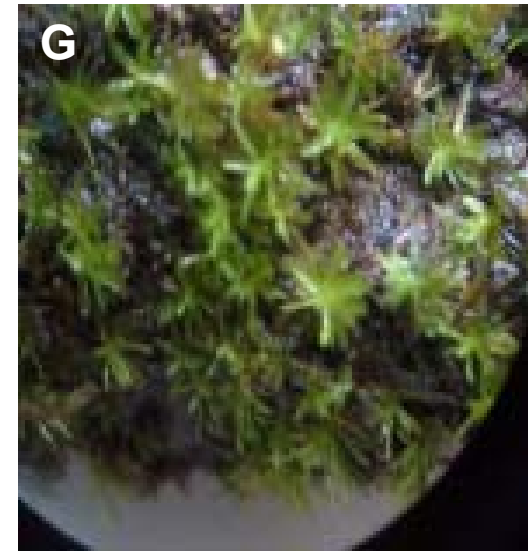

Calymperes cougiense

Gambar 1. Beberapa jenis lumut bersubstrat marga Pandanus, di Taman Nasional Ujung Kulon, Banten.

pertumbuhan lumut dibandingkan jenis pandan lainnya. Di lokasi penelitian, bidur tumbuh di lingkungan yang relatif lembab di pinggir pantai. Keadaan lembab dan teduh di sekitar tempat tumbuhnya bidur diakibatkan oleh banyaknya pepohonan yang cukup tinggi dan bertajuk melebar. Kelembaban dan cahaya merupakan faktor lingkungan yang penting dan besar pengaruhnya terhadap pertumbuhan lumut khususnya di daerah tropis (Richards 1984). Dengan demikian lingkungan di sekitar bidur merupakan lingkungan yang cocok dan memungkinkan ditemukannya pertumbuhan lumut yang lebih banyak dibandingkan dengan lingkungan pandan dari jenis lainnya. Lumut yang menempel pada bidur ditemukan pada bagian perakaran, sedang bagian batang dan daun tidak ditemukan. Permukaan akar bidur pada umumnya kasar dan kadang-kadang retak. Dengan kondisi seperti ini memungkinkan untuk singgahnya spora atau kuncup (gemma) lumut dan air 
di celah-celah retakan. Adanya permukaan perakaran yang retak-retak dan didukung oleh lingkungan yang lembab serta sinar matahari cukup maka kuncup dan spora lumut dapat berkecambah dan meneruskan kehidupannya. Sedangkan di bagian batang dan daun bidur tidak ditemukan lumut karena permukaannya halus dan licin sehingga tidak memungkinkan singgahnya spora atau kuncup lumut dan air, meskipun kelembaban sekitarnya mendukung untuk perkecambahannya. Perawakan bidur di lokasi penelitian menunjukkan adanya percabangan dan diduga pada ketiak percabangan pohon akan ditemukan lumut. Namun ternyata pada percabangan pohon bidur tidak ditemukan. Keadaan seperti ini dapat terjadi karena pada ketiak percabangan mempunyai permukaan yang halus dan tidak ada serasah yang tersangkut pada ketiak percabangan tersebut. Dengan demikian spora-spora lumut yang terbawa angin dan jatuh pada permukaan ketiak percabangan bidur tidak dapat tumbuh atau hilang tertiup oleh angin laut. Jenisjenis lumut yang ditemukan pada bidur sebanyak enam jenis, jumlah ini merupakan paling banyak dibandingkan dengan jenis-jenis pandan lainnya. Enam jenis lumut tersebut adalah Lopholejeunea eulopha, Leucolejeunea xanthocarpa, Frullaniasp, Bazzaniasp (kelompok lumut hati /hepatic), Calymperes crassinerve, Calymperes cougiense (kelompok lumut daun/musci). C. cougiense dan $C$. crassinerve (Gambar 1) umumnya banyak tumbuh di hutan dataran rendah dekat pantai dengan kondisi lingkungan agak terbuka. C. cougiense (lampiran gambar g) dilaporkan sebagai satu jenis lumut yang ditemukan tumbuh di kawasan Polinesia dan umumnya melimpah di kawasan Malesia (Eddy 1990).

Berbeda dengan cangkuang (Pandanus furcatus) dan pandan (Pandanus tectorius). Cangkuang ( $P$. furcatus) ditemukan tumbuh di hutan dataran rendah dan agak jauh dari pantai. Lingkungan sekitarnya berupa pepohonan yang cukup tinggi dan beberapa jenis palem-paleman (Arecaceae). Lantai hutan berupa tanah becek dan selalu berair jika laut pasang. Kondisi seperti ini tidak memungkinkan ditemukan lumut pada lantai hutan maupun bagian perakarannya oleh karena sporaspora lumut yang jatuh akan mudah terbawa oleh pasang surutnya air laut yang tingginya dapat mencapai pangkal perakaran cangkuang. Adapun lumut yang ditemukan tumbuh menempel pada bagian batangnya. Jenis-jenis lumut yang ditemukan tumbuh pada cangkuang adalah Fissidens teysmanianus dan Vesicularia montagnei. F. teysmanianus (lampiran gambar d) merupakan lumut akrokarpus (tumbuh tegak) yang tumbuh soliter pada batuan lembab di tempat terbuka, jenis ini dilaporkan endemik di Jawa (Eddy 1988).

Pandan ( $P$. tectorius) ditemukan di sepanjang pantai selatan dengan lingkungan terbuka, kering dan panas. Lumut yang tumbuh sangat sedikit, hanya ditemukan pada beberapa pohon pandan yang tumbuh agak ke arah dalam dan bukan pada individu yang berdekatan langsung dengan pantai. Hanya satu marga lumut yang ditemukan yaitu marga Frullania,. Marga ini termasuk dalam kelompok lumut hati berdaun dan tumbuh pipih melekat pada kulit batang pohon dengan kondisi lingkungan yang kering dan terbuka. Meskipun demikian faktor kelembaban masih sangat besar juga pengaruhnya terhadap pertumbuhan dan populasinya. Hal ini dapat dibuktikan dengan tidak ditemukannya anggota dari marga ini dan jenis-jenis lumut lainnya pada individu pandan yang tumbuh berdekatan dengan pantai.

Pandanus nitidus merupakan satu jenis pandan yang ditemukan tumbuh di hutan dataran rendah agak ke arah pantai dengan kondisi lingkungan yang lembab dan terbuka, disekitaranya banyak ditumbuhi oleh semak belukar dan pepohonan yang relatif tinggi. Lantai hutan di sekitar pandan ini becek. Lumut pada pandan ini hanya ditemukan di bagian batang bagian bawah dan akar, sedangkan di batang bagian atas yang lingkungan sekitarnya benar-benar terbuka tidak ditemukan. Adapun jenis lumut yang ditemukan adalah Calymperes cougiense, Thuidium kiasense dan Radula $\mathrm{sp.}$

Apabila ditinjau dari populasinya maka lumut yang dominan tumbuh di marga Pandanus adalah anggota suku Frullaniaceae dan Calymperaceae. Suku Frullaniaceae merupakan lumut hati yang ditemukan menempel kuat pada habitatnya dan bentuk pertumbuhannya pipih, anggota dari suku ini umumnya tahan terhadap kekeringan. Pada kondisi kering tumbuhan ini tampak melekat kuat sehingga sangat sulit dipisahkan dengan substratnya. Sedangkan suku Calymperaceae merupakan kelompok lumut daun yang mempunyai kisaran habitat cukup luas dan cara perbanyakan yang bervariasi. Selain menggunakan spora yang dihasilkan oleh generasi sporofit juga dapat 
memperbanyak diri secara vegetatif dengan menggunakan kuncup (gemma) yang terdapat pada ujung-ujung pertulangan daunnya (Yamaguchi et al, 2005).

\section{KESIMPULAN}

Tercatat 4 jenis Pandanus ditemukan di lokasi penelitian yaitu Pandanus dubius, Pandanus furcatus, Pandanus tectorius dan Pandaus sp. Populasi yang melimpah adalah jenis Pandanus tectorius yang banyak tumbuh di sepanjang tepi pantai selatan wilayah resort Karang Ranjang. Umumnya lumut ditemukan di pandan yang tumbuh dengan kondisi lingkungan lembab dan cukup cahaya matahari dan permukaan tumbuhan kasar. Dengan demikian faktor kelembaban dan cahaya matahari serta kasar halusnya permukaan pohon pandan sangat berpengaruh terhadap pertumbuhan lumut. Pandanus dubius merupakan habitat terbaik untuk lumut karena mempunyai permukaan perakaran yang kasar. Lumut yang ditemukan diperkirakan ada 15 jenis, 9 jenis diantaranya telah teridentifikasi hingga nama jenisnya. Fissidens teysmanianum merupakan jenis endemik di Jawa serta Calymperes cougiense merupakan jenis yang melimpah di kawasan Malesia dan juga ditemukan di kawasan Polinesia.

\section{UCAPAN TERIMAKASIH}

Dengan selesainya penelitian ini, penulis mengucapkan terimakasih kepada Kepala Pusat Penelitian Biologi melalui proyek DIPA 2006 dengan sub kegiatan "Revisi suku-suku terpilih" yang telah memberikan dana dan kesempatan kepada penulis untuk melakukan penelitian. Ucapan terimakasih juga disampaikan kepada Kepala Taman Nasional Ujung Kulon yang telah memberikan ijin dan fasilitas kepada penulis selama melakukan penelitian. Di samping itu Penulis juga mengucapkan terimakasih kepada Kepala Resort Karang Ranjang beserta stafnya dan semua teman anggota tim peneliti yang telah bekerjasama selama melakukan kegiatan penelitian, serta semua pihak yang telah membantu hingga selesainya penelitian dan penulisan naskah ini sampai dapat dipublikasikan.

\section{DAFTAR PUSTAKA}

Bartram, E.B. 1939. Mosses of Philippine. The Philippine Journal of Science 68: 1-435.

Eddy, A. 1988. A Handbook of Malesian Mosses Volume 1. London: Natural History Museum Publications.

Eddy, A. 1990. A Handbook of Malesian Mosses Volume 2. Natural History Museum Publications London.

Hommel, P.W. F.M., 1987. "Landscape-Ecology of Ujung Kulon (West Java, Indonesia) Privately published by Patrick W. F. M. Hommel, Wageningen.

Maulana, H., Lana Sari, A. N. Susdihanto. 2004. Menjelajah Situs Alam Warisan Dunia Taman Nasional Ujung Kulon. Banten: Balai Taman Nasional Ujung Kulon.

Richards,P.W. 1984. The ecology of tropical forest Bryophyte. Di dalam: Schuster R.M. (ed.). Manual of Bryology Vol. 2. Nichinan.

Rugayah, A. Retnowati, F.I. Windadri, A. Hidayat. 2004 Pengumpulan data Taksonomi. Di dalam: Rugayah, E.A. Widjaja, Praptiwi (Eds.). Pedoman Pengumpulan Data Keanekaragaman Flora. Pusat Penelitian Biologi-Lembaga Ilmu Pengetahuan Indonesia.

So.,M.L. 1995. Mosses and Liverworts of Hongkong Volume 1. Heavenly. Hongkong: People Depot.

Sriyanto, A., D. Suganda, E. Widjanarti, D. Sutaryono, A. Hermawan, G. Suharyanto (Eds.). 2003. Buku Panduan 41 Taman Nasional di Indonesia. Indonesia: Departemen Kehutanan Republik Indonesia, UNESCO dan CIFOR.

Yamaguchi, T., F.I. Windadri, I. Haerida, H. Simbolon, A. Kunimura, H. Miyawaki, H. Shimizu. 2005. Effect of forest fires on Bryophyte flora in East Kalimantan, Indonesia. Phyton Annales Rei Botanica 45: 561-567. 